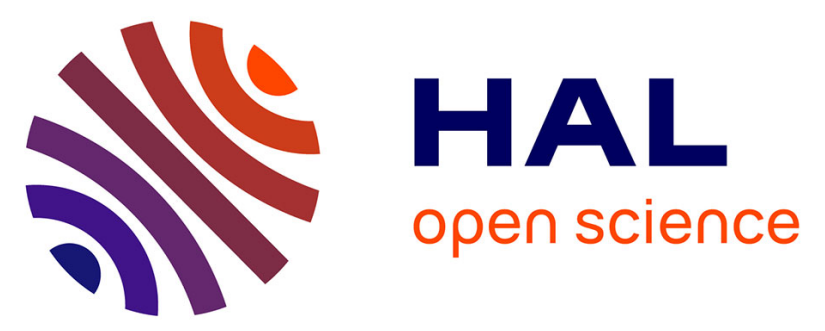

\title{
Adjustment of Cell Adhesion on Polyurethane Structures via Control of the Hard/Soft Segment Ratio
}

Gaëtan Lutzweiler, Julien Barthes, Nihal Engin Vrana, Michel Rawiso, Benoît

Louis, Josselin Mayingi, Albane Carre, Wiebke Drenckhan, Pierre Schaaf

\section{- To cite this version:}

Gaëtan Lutzweiler, Julien Barthes, Nihal Engin Vrana, Michel Rawiso, Benoît Louis, et al.. Adjustment of Cell Adhesion on Polyurethane Structures via Control of the Hard/Soft Segment Ratio. Macromolecular Materials and Engineering, 2020, 305 (5), pp.2000093. 10.1002/mame.202000093 . hal-03009461

\section{HAL Id: hal-03009461 \\ https://hal.science/hal-03009461}

Submitted on 17 Nov 2020

HAL is a multi-disciplinary open access archive for the deposit and dissemination of scientific research documents, whether they are published or not. The documents may come from teaching and research institutions in France or abroad, or from public or private research centers.
L'archive ouverte pluridisciplinaire $\mathbf{H A L}$, est destinée au dépôt et à la diffusion de documents scientifiques de niveau recherche, publiés ou non, émanant des établissements d'enseignement et de recherche français ou étrangers, des laboratoires publics ou privés. 


\title{
Adjustment of Cell Adhesion on Polyurethane Structures via Control of the Hard/Soft Segment Ratio
}

\author{
Gaëtan Lutzweiler, * Julien Barthes, Nihal Engin Vrana,* Michel Rawiso, Benoît Louis, \\ Josselin Mayingi, Albane Carre, Wiebke Drenckhan, and Pierre Schaaf
}

Creating substrates with a similar composition that can either prevent or promote cell adhesion is still a challenging feat. Here, it is shown that a strikingly simple method of tuning the amount of hard segments or isocyanate index $\left(\mathrm{NCO}_{\text {ind }}\right)$ of a polyurethane (PU) film allows to modulate cell adhesiveness. PU films are synthesized with $\mathrm{NCO}_{\text {ind }}$ of 75, 100, 200, 300 and 400 corresponding to ratios of isocyanate to hydroxyl functions of $0.75,1$, $2,3,4$, respectively. The adhesive capacity of NIH 3 T3 fibroblasts (3T3) and Wharton's jelly mesenchymal stem cells (WJMSCs) are dependent on the $\mathrm{NCO}_{\text {ind }}$. For $\mathrm{NCO}_{\text {ind }}$ below 300 , no cell adhesion can be observed regardless of the cell type, whereas for $\mathrm{NCO}_{\text {ind }}$ of 300 and 400 cells adhere to the PU surface. WAXS and small angle X-ray scattering (SAXS) studies reveal that variations of $\mathrm{NCO}_{\text {ind }}$ allows to modulate the phase separation in $\mathrm{PU}$ films. Porod's law shows that for $\mathrm{NCO}_{\text {ind }}$ of 300 and 400 , the hard-soft segment interface is sharp. Conversely, samples with smaller $\mathrm{NCO}_{\text {ind }}$ present diffuse interfaces. Hence, the morphology of the interface between hard and soft domains appears to be a critical feature that correlates with the adhesion capacity of cells.

\section{Introduction}

Cell attachment is considered as the first step needed to trigger the proliferation and afterward the colonization of porous scaffolds. Cell adhesion is often mediated by integrins, which are transmembrane proteins composed of $\alpha$ and $\beta$ subunits that recognize specific sequences of peptides to which they can bind to. ${ }^{[1]}$ The most studied adhesion peptide sequence is the RGD (Arg-GlyAsp) sequence that is naturally present on some extracellular proteins. ${ }^{[2]}$ Synthetic materials do not have such adhesive motifs. Hence, often biomaterial surfaces are coated or functionalized with proteins or peptides to enhance cellular adhesion. ${ }^{[3-5]}$ Polyurethane (PU) is widely used in the medical field due to its biocompatibility as well as the advantageous mechanical properties that can be tailored to match the ones of a given tissue. ${ }^{[6,7]}$ Polyurethanes are produced by the reaction between a polyol, and an isocyanate, as shown in Figure 1. Sometimes, a chain extender is used to increase the chain length of the final polymer. ${ }^{[8]}$ Polyols have higher molecular weights than isocyanate, they have a high mobility and flexibility of their chains, which is why they are named as "soft segments." Isocyanates provide stiffness to the polymer and are often called "hard segments." Hard and soft segments can separate into two distinct phases (due to their incompatibility) within the polymer matrix where hard segments can self-arrange by $\pi$-stacking or hydrogen bonding forming distinct domains randomly distributed in the soft segment matrix. Phase separation depends on several factors such as the thermal history of the polymer ${ }^{[9]}$ or the molecular structure of both the hard and the soft segments. ${ }^{[10]}$ This phase separation has already been studied in the past by X-Ray photoelectron spectroscopy (XPS), ${ }^{[11]}$ Fourier Transformed Infrared Spectroscopy (FTIR), ${ }^{[9]}$ and Small Angle X-ray Scattering (SAXS) ${ }^{[12]}$ It was shown to influence the mechanical properties. ${ }^{[13]}$ To our knowledge, only few examples are reported in the literature where the influence of this microphase separation on cell attachment and proliferation on the PU surface is investigated. Yuan et al. ${ }^{[14]}$ produced poly(caprolactone)-based PU and modified the hard segment fraction in their formulation. They showed

DOI: 10.1002/mame.202000093 
a)

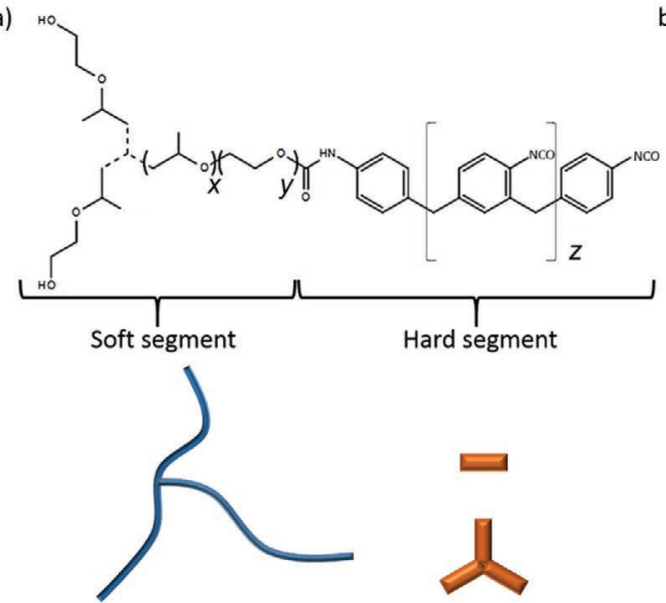

b)

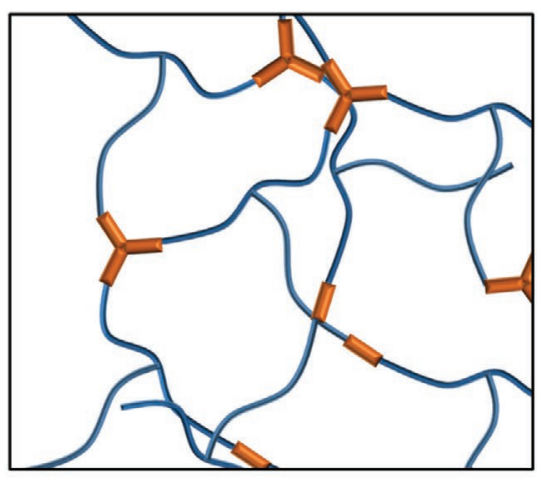

Figure 1. a) Chemical structure of the PU obtained from the reaction of a polyether triol composed of polypropylene oxide (PPO) $x \approx 30$ backbone end capped with polyethylene oxide PEO $y \approx 7$ forming the soft segment units and the polyMDI with $z \approx 0$ or 1 forming the hard segment units. b) Schematic representation of the $\mathrm{PU}$ with the main building blocks.

that endothelial cells form a well-organized network on films undergoing microphase separation within the bulk compared to homogenous PU films. The authors argued that cells were sensitive to the phase segregation and especially to the hard segment domains with a higher local stiffness that could help them to form stable focal contacts. The ability of the distinct domains containing hard segments to support cell adhesion was also demonstrated by Nalluri et al. ${ }^{[15]}$ They generated polyurethanes having poly(ethylene glycol) as soft segments (which prevent cell adhesion), and hard segments that were composed of either hexamethylene diisocyanate (HDI) or 4,4'-methylenebis (cyclohexyl isocyanate) (HMDI). While HDI-based PU exhibited a phase separation, HMDI-based PU showed that hard and soft segments were more homogenously distributed. This was attributed to the fact that HMDI cannot self-organize due to steric hindrance. In another study, Mesenchymal Stem Cells (MSCs) were shown to make stable focal contacts on PU presenting phase separation which was also attributed to the interaction between cells and the hard segment domains. Furthermore, Mi et al. ${ }^{[16]}$ used two commercial polyurethanes with two hard segment fractions. They showed that the polymers become increasingly hydrophobic when the hard segment content increases, and that the protein adsorption is higher when the hard segments content decreases. They demonstrated that 3T3 fibroblasts showed better viability on PU having a higher hard segment fraction despite the fact that those films were more hydrophobic and that less proteins were adsorbed on their surface. Even if these authors did not investigate whether some phase separation is present within the polymer, these findings highlight the fact that cells respond differently regarding the microstructure of the PU underneath. The study therefore aims to investigate this effect in more detail.

We showed in a previous study that PU scaffold appears as a good candidate for tissue engineering applications but cell colonization and survival required surface treatments of PU. ${ }^{[17]} \mathrm{As}$ other studies reported that PU by itself is a poor substrate to support cell adhesion, ${ }^{[18,19]}$ it becomes important to understand how cell adhesiveness is correlated to PU microstructure and how to improve it especially for tissue engineering where cell adhesion is necessary to obtain a fully colonized and functional scaffold. ${ }^{20]}$

In that purpose, we synthesized PU films with different isocyanate index $\left(\mathrm{NCO}_{\text {ind }}\right)$ (i.e., the ratio of isocyanate to hydroxyl groups times 100 added during the synthesis) ranging from 75 to 400 . We investigated how the changes in isocyanate content affect the microstructure of the PU and correlate this with the capacity of NIH 3T3 fibroblasts (3T3) and Wharton's Jelly mesenchymal stem cells (WJMSCs) to attach to the PU surface. Higher $\mathrm{NCO}_{\text {ind }}$ result in more cell attachment and we aimed to determine the optimal index for cellular adhesion. the control of the adhesion capacity of cells by varying the $\mathrm{NCO}_{\text {ind }}$ appears to be a simple way to overcome the poor adhesive properties of PU without the need of supplementary surface treatments. We characterize the obtained films in terms of wettability, protein adsorption, surface and bulk chemistry, and phase separation of hard and soft segments within the matrix to establish a correlation between the cellular response to the material and its structural features.

We show for the first time that cell adhesion on PU surface depends on the nature of the interface between hard and soft segments and that the nature of the interface is easily controlled by the $\mathrm{NCO}_{\text {ind }}$. Finally, we extrapolate this flat model to a 3D porous material as a model system for tissue engineering and we investigate if cell colonization can be improved by the modulation of the $\mathrm{NCO}_{\text {ind }}$.

\section{Experimental Section}

\subsection{Polyurethane Film Synthesis and Casting}

Polyurethane films were obtained by mixing all the precursors in the "one shot" method. As sketched in Figure 1a, a polyether triol composed of poly(propylene oxide) (PPO) end-capped with poly(ethylene oxide) (PEO) units (Voranol 6150, Dow, MW 6000, 
$\mathrm{OH}$ number $\left(\mathrm{OH}_{\text {numb }} 29 \mathrm{mg} \mathrm{KOH} \mathrm{g}{ }^{-1}\right)$ and a Poly(methylene Polyphenyisocyanate) (polyMDI Voranate M220b, Dow, with $30.9 \%$ of free NCO (\%NCO) were mixed together under vigorous stirring at 20K rpm for 3 min using an Ultra Turrax (IKA T25). $1 \mathrm{~mL}$ of this mixture was then cast into the bottom of a 6 well-plate, leading to films of $0.5 \mathrm{~mm}$ thickness. All films were let to solidify for $48 \mathrm{~h}$ at room temperature. The $\mathrm{NCO}_{\text {ind }}$ were obtained by the following method given by Hepburn ${ }^{[21]}$ in which one calculates first the equivalent weights of polyol and isocyanate in order to take into account the differences in their respective functionality.

The polyol equivalent weight EW was calculated via

$E W_{\mathrm{OH}}=\frac{56100}{\mathrm{OH}_{\text {numb }}}=1934.5 \mathrm{~g}$

where 56100 is the molecular weight of potassium hydroxide expressed in milligrams (used in the titration to estimate the number of free hydroxyl groups). In this case, only one polyol was used and neither water nor catalyst that could contribute to increase the $\mathrm{OH}$ number was added. The equivalent weight of polyMDI was determined as

$E W_{\mathrm{NCO}}=\frac{42}{\% \mathrm{NCO}}$

where 42 is the molecular weight of the isocyanate NCO function. In this case the equivalent weight of the isocyanate $E W_{\mathrm{NCO}}=136 \mathrm{~g}$. From the equivalent weights, polyurethane films were prepared with isocyanate/hydroxyl function ratios of $0.75: 1,1: 1,2: 1,3: 1$, and $4: 1$ corresponding to $\mathrm{NCO}_{\text {ind }}$ of 75 , $100,200,300$, and 400 . The isocyanate index is by convention 100 times the ratio of free isocyanate functions to free hydroxyl functions that are contained in the initial batch before the reaction. ${ }^{22}$ ]

The well plates with PU films at the bottom were sterilized by UV radiation for $15 \mathrm{~min}$.

\subsection{Generation of Porous Scaffold}

PU scaffolds were generated by a sphere templating approach already described in the previous paper. ${ }^{[1]}$ Briefly, paraffin spheres were obtained by an emulsion-dispersion method. $10 \mathrm{~g}$ of melting paraffin (Fischer Scientific, mp 58-62 ${ }^{\circ} \mathrm{C}$ ) was added to $400 \mathrm{~mL}$ water at $70{ }^{\circ} \mathrm{C}$ under vigorous stirring $(950 \mathrm{rpm})$ and stabilized by 3 g poly(vinyl alcohol) PVA (Sigma, MW 31 000-50 $00089 \%$ hydrolysate). After $10 \mathrm{~min}, 400 \mathrm{~mL}$ of ice cold water was added which solidified instantly the paraffin droplets. Those beads were directly sieved using stainless sieves to obtain bead sizes between 125 and $200 \mu \mathrm{m}$ (133 $\mu \mathrm{m}$ on average) for the experiments. These paraffin beads were packed in a mold (petri dish of $34 \mathrm{~mm}$ in diameter, VWR) and put in an oven for $1 \mathrm{~h}$ at $43{ }^{\circ} \mathrm{C}$ to promote sintering which created a neck at the contact point between beads. A freshly prepared polyol-isocyanate mixture (Section 2.1) was then cast onto the bead assembly and let to infiltrate and solidify. Finally, the paraffin beads were dissolved by Sohxlet extraction in $n$-hexane at $80{ }^{\circ} \mathrm{C}$ for $4 \mathrm{~h}$. The resulting porous scaffold was left to dry under a fume hood for $12 \mathrm{~h}$.

\subsection{Expansion of Cells and Cell Seeding}

NIH 3T3 fibroblasts (ATCC) were suspended in culture media DMEM (Dulbecco's modified Eagle's Media) supplemented with $10 \%$ (v/v) of decomplemented Foetal Bovine serum (FBS) and $1 \%$ penicillin/streptomycin $(\mathrm{v} / \mathrm{v})$ and let to expand in 175 T-flasks within a humidified incubator at $37{ }^{\circ} \mathrm{C}, 5 \% \mathrm{CO}_{2}$. WJMSCs were isolated from umbilical cords of consenting patients (Authorization body: Inserm, ITMO Santé Publique Pôle Recherche Clinique (PRC)), Authorization number: DC-2015-2364) using a procedure described elsewhere. ${ }^{[23]}$ WJMSCs were suspended in $\alpha$-MEM Eagle (Gibco) supplemented with $20 \%$ of decomplemented Fetal Bovine Serum (FBS), $1 \%$ penicillin/streptomycin/amphotericin, and $1 \%$ of L-glutamine and let to proliferate in 175 T-flasks at $37{ }^{\circ} \mathrm{C}$, $5 \% \mathrm{CO}_{2}$. WJMSCs were seeded at passage 5 while fibroblasts were seeded at passage $16.5 \mathrm{~mL}$ of a trypsin-EDTA solution was used to take off the cells and the solution was neutralized with cell media after 6 min in the incubator. 120000 cells per well plate were seeded in $4 \mathrm{~mL}$ of appropriate culture media (depending on the cell type as aforementioned).

\subsection{Calcein-Green Staining}

Cells were pre-labeled with Calcein-green just before being seeded. Cells were suspended in serum free media, and $5 \mu \mathrm{L}$ of calcein (Vybrant Cell Adhesion Assay kit V-13181, ThermoFisher) per million of cells was added and the cell suspension was placed in an incubator at $37{ }^{\circ} \mathrm{C}$ for $30 \mathrm{~min}$ and protected from light. Afterward, cells were centrifuged and resuspended in classical culture media prior to be seeded.

\subsection{DAPI/Phalloidin Staining}

Cells were washed two times in PBS and fixed in a 4\% paraformaldehyde in PBS solution for $30 \mathrm{~min}$ at room temperature. The fixation solution was then removed and samples were kept in PBS at $4{ }^{\circ} \mathrm{C}$ before staining. Cell membrane was first permeabilized with a solution of $0.1 \%$ Triton X-100 in PBS for $10 \mathrm{~min}$, followed by two washing steps with PBS and incubated with a solution of 1\% v/v of Bovine Serum Albumin (BSA) for $20 \mathrm{~min}$. Actin filaments were then stained with a solution of fluorescent molecule conjugated Phalloidin (Alexa Fluor 568) at $1 / 40 \mathrm{v} / \mathrm{v}$ in PBS for $30 \mathrm{~min}$. Then, samples were washed two times with PBS for $5 \mathrm{~min}$ and subsequently counterstained with a DAPI (4',6 diamidino-2-phenylindole, PromoKine) solution at a concentration of $1 / 100 \mathrm{v} / \mathrm{v}$ in PBS for $5 \mathrm{~min}$. At the end, samples were washed two times in PBS for $5 \mathrm{~min}$ and kept in PBS at $4{ }^{\circ} \mathrm{C}$. DAPI/Phalloidin staining was performed after 7 days of culture in the case of WJMSCs seeded in porous scaffold and after $24 \mathrm{~h}$ of culture for 3T3 fibroblasts and WJMSCs seeded on PU films.

\subsection{X-Ray Photoelectron Spectroscopy}

The X-ray photoelectron spectroscopy (XPS) measurements were carried out in an ultrahigh vacuum (UHV) spectrometer 
(Thermo VG Multi lab ESCA 3000) spectrometer equipped with a CLAM4 (MCD) hemispherical electron analyzer. A dual anode Al $\mathrm{K} \alpha \mathrm{X}$-ray source $(1486.6 \mathrm{eV})$ was used as incident radiation. Survey and high resolution spectra were recorded in constant pass energy mode (100 and $20 \mathrm{eV}$, respectively).

\subsection{Fourier Transform Infrared Spectroscopy}

FTIR was carried out for the solid PU films with a Bruker Vertex 70 instrument equipped with an attenuated total reflectance (ATR) module. Scans were performed from 400 to $4000 \mathrm{~cm}^{-1}$ with a spectral resolution of $2 \mathrm{~cm}^{-1}$.

\subsection{Contact Angle Measurement}

Surface wetting properties of the PUs with various $\mathrm{NCO}_{\text {ind }}$ were obtained by static contact angle measurements with purified water (Milli-Q) at room temperature. The sessile drop technique (Attension theta, Biolin Scientific) was used and the values of the contact angles were obtained by image treatment using the software Oneattension. Each experiment was repeated three times to ensure the reproducibility.

\subsection{Confocal Microscopy}

Confocal images were taken after $24 \mathrm{~h}$ of culture using an inverted Zeiss LSM 710 microscope. Objectives x10 and x20 were used to visualize the cells on the films. The six well plate coated with the PU films was directly placed under the microscope. Excitation/emission wavelengths were 489/556, 578/600, and 360/460 nm for Calcein-green, Alexa Fluor 568 Phalloidin and DAPI, respectively. For FITC-BSA detection to evaluate the amount of protein adsorbed on PU surface, an area of $849 \mu \mathrm{m} \times 849 \mu \mathrm{m}$ was scanned using the same gain (636) for all images. The excitation wavelength was $488 \mathrm{~nm}$ at $17.5 \%$ intensity and the emission wavelength was $496-563 \mathrm{~nm}$.

\subsection{Mechanical Testing}

PU films (15 mm thick) were shaped into dumbbells $(90 \mathrm{~mm}$ long) and stress-strain curves were obtained according to the NF EN ISO 527-1 and NF EN ISO 527-2 standards. Traction tests were performed using a machine of universal assays (Zwick) mounted with a sensor of $200 \mathrm{~N}$. A preload of $1 \mathrm{~N}$ was applied and the stretching was performed at a rate of $50 \mathrm{~mm}$ min $^{-1}$ until break. The Young's modulus was obtained by calculating the initial slope of the stress-strain curves in the linear regime.

\subsection{Protein Adsorption Tests}

Two tests were conducted to ensure that the results were accurate and reliable. The first method was the Bradford method.
Polyurethane samples were cut into discs having $13 \mathrm{~mm}$ in diameter and $5 \mathrm{~mm}$ height. PU samples with $\mathrm{NCO}_{\text {ind }}$ from 75 to 400 were first immersed in $2 \mathrm{~mL}$ FBS for $24 \mathrm{~h}$. After that, samples were rinsed with PBS, and placed in a 24 well plate. The adsorbed proteins were then detached by using a detergent solution (3 $\mathrm{m}$ urea (Aldrich), and sodium dodecyl sulfate, SDS 5\% (Sigma-Aldrich) in PBS) overnight. Aside, a calibration curve was generated by using bovine serum albumin BSA (Sigma) diluted at $1 \%$ as the standard protein since the serum in culture media is mainly composed of BSA. The second method consisted in immersing PU samples with different $\mathrm{NCO}_{\text {ind }}$ in $1 \mathrm{~mL}$ of a solution of $0.25 \mathrm{mg} \mathrm{mL}^{-1}$ of FITC-BSA in PBS for $30 \mathrm{~min}$ in the dark. Samples were then washed with PBS and left in PBS à $4{ }^{\circ} \mathrm{C}$ until observation with confocal microscopy as described above. Fluorescent intensity was recorded at the surface of each sample using Teflon as control. Although the exact concentration value cannot be obtained, the fluorescent intensity is proportional to the amount of adsorbed proteins, therefore, one expects the same profile as the Bradford method.

\subsection{Atomic Force Microscopy}

Polyurethane films were cast in a petri dish. Once dried, samples were cut into discs having $13 \mathrm{~mm}$ in diameter and $1 \mathrm{~mm}$ height. Samples were placed under the AFM in air at room temperature.

Experiments were carried out with a multimode AFM 8 mounted with a controller Nanoscope V 64 bits from Bruker. They were conducted in peakforce tapping mode by using a Probe Scan Asyst fluid $(0.7 \mathrm{Nm})$ probe from Bruker. Surface roughness was determined using the software Nanoscope Analysis 1.5 and expressed as root mean square value (RMS).

\subsection{Small Angle X-Ray Scattering}

SAXS experiments were performed with a diffractometer developed by Molecular Metrology (Elexience in France) that uses a Rigaku Micromax 007HF generator with a copper-rotating anode. The wavelength of the incident X-ray beam is $\lambda=1.54 \AA$. This diffractometer operates with a pinhole collimation of the X-ray beam focused by a multilayer optic designed by Osmic and a two-dimensional gas-filled multiwire detector. The sample-detector distance was set at $0.7 \mathrm{~m}$, leading to a range of scattering vectors covered by the experiment $0.01<q<0.32 \AA^{-1}$. The scattering vector $q$ is defined by $q=(4 \pi / \lambda) \sin (\theta / 2)$, where $\lambda$ is the wavelength of the incident beam and $\theta$, the scattering angle. The $q$-resolution related to the beam size on the sample and the beam divergence roughly $0.005 \AA^{-1}$. Copolymer films of thicknesses of $1 \mathrm{~mm}$ were studied. Measurements were performed at room temperature.

\subsection{Wide Angle X-Ray Scattering}

WAXS experiments were carried out with the same diffractometer as the SAXS by using Phosphor imaging plates from 
Molecular dynamics as detectors. These plates were set at $0.06 \mathrm{~m}$ from the samples, allowing to explore scattering vectors ranging from $q=0.05$ to $3.5 \AA^{-1}$. The same copolymer films of thicknesses $1 \mathrm{~mm}$ were used in the same positions with respect to the incident X-ray beam than for the SAXS experiments (Section 2.13). Measurements were also performed at room temperature. WAXS measurements allow to investigate arrangements at the atomic level while SAXS measurements can probe larger length scale such as nano domains in the polymer.

\subsection{Data Treatment}

For SAXS, all data were treated according to standard procedures for isotropic small angle X-ray scattering. ${ }^{[24]}$ After radial averaging, the spectra were corrected from electronic noise of the detector, empty cell, absorption and sample thickness. A $55 \mathrm{Fe}$ source was used for the corrections of geometrical factors and detector cells efficiency as well as a Silver Behenate sample, for the $q$-calibration. The normalization to the unit incident flux was then obtained by using water or Lupolen (polyethylene) as standard samples. Nevertheless, such measurements on an absolute scale, scattered intensities $I(q)$ expressed in $\mathrm{cm}^{-1}$, were not perfectly achieved for the WAXS experiments in this case. The spectra were then locked onto the related SAXS ones. After all these data treatments, the scattered intensities at low $q$-values only associated with the concentration fluctuations, should still be corrected from the scattering related to the density fluctuations. This last correction was done through the subtraction of an additional constant that allows observing a $q^{-4}$ scattering behavior characteristic of the existence of sharp interfaces for some samples. Indeed, the "far-away point" method, ${ }^{[25]}$ which assumes that the density fluctuations are almost identical for the background and the film could not be used here as the density fluctuations were already taking place in a q-range in which the concentration fluctuations are not still negligible $(q \approx$ $\left.0.3 \AA^{-1}\right)$. According to such a procedure, the scattered intensity $I(q)$ at low $q$-values, containing all the structural information, is obtained for each PU film.

\subsection{Analysis of Elementary Scatterers for X-Ray Experiments}

The characteristics of the elementary scatterers involved in the SAXS experiments are listed in Table $1 . Z$ is the number of electrons of the elementary scatterer (E.S.). The coherent X-ray scattering length $a(\mathrm{~cm})$ of the E.S. is proportional to $Z$ and defined by the relation

$a=0.28210^{-12} Z$

The coherent X-ray scattering length density $\rho_{\text {sl }}(\mathrm{cm})$ is then obtained through the equation

$\rho_{\mathrm{sl}}=\frac{a}{v} N_{A}$

where $v\left(\mathrm{~cm}^{3} \mathrm{~mol}^{-1}\right)$ is the molar volume of the E.S. and $N_{A}$ $\left(\mathrm{mol}^{-1}\right)$ Avogadro's number.

The molar volumes of most of the E.S. involved in the studied polyurethanes are listed in the book of Van Krevelen et al. ${ }^{[26]}$ and summarized in Table 1 . For the missing ones the additivity law of the partial molar volumes was used.

The contrast between the hard and soft segments (- $\mathrm{CONH}-\mathrm{Ph}-\mathrm{CH}_{2}-\mathrm{Ph}-\mathrm{NHOCO}-$ and $-\mathrm{CH}_{2}-\mathrm{CH}\left(\mathrm{CH}_{3}\right)-\mathrm{O}-$ ) is then $\Delta \rho^{2}=\left(\rho_{\mathrm{s}}-\rho_{\mathrm{h}}\right)^{2}=3.276110^{20} \mathrm{~cm}^{-4}$, assuming an amorphous state for both segments. This is justified by the lack of Bragg peaks in Figure 8. It becomes $\Delta \rho^{2}=\left(\rho_{\mathrm{s}}-\rho_{\mathrm{h}}\right)^{2}=9.985610^{20} \mathrm{~cm}^{-4}$, when the hard segments are considered in their crystalline state.

\subsection{Viability Assay}

Cytotoxicity of the different PU samples was tested toward NIH 3T3 fibroblasts via indirect contact method. This experiment was performed on extraction vehicle. PU samples were immersed in $1 \mathrm{~mL}$ of cell culture medium (DMEM supplemented) for $24 \mathrm{~h}$ at $37{ }^{\circ} \mathrm{C}$ in order to extract all potential harmful monomers (extraction vehicle) In the same time, $\mathrm{NIH}$ 3T3 cells were seeded in a 24 well plate at a density of 60000 cells per well to obtain a cell layer of $80 \%$ confluence after $24 \mathrm{~h}$. Then after $24 \mathrm{~h}$, the extraction vehicle is transferred on the cell layer and let in contact for $24 \mathrm{~h}$. MTT test (bromure 3-(4,5-dimethyltiazol-2-yl)-2-5 diphenyl tetrazolium) is then performed to assess the metabolic activity of cells and determine the percentage of viability. Viability is normalized with a control which is a cell layer cultured for $48 \mathrm{~h}$ without exposure with to extraction vehicle. According to the test standards, a sample is considered cytotoxic if the viability normalized with control is less than $70 \%$.

Table 1. Characteristic parameters of the various elementary scatterers involved in this study. $Z$ is the number of electrons; $a$ is the coherent $X$-ray scattering length (see Equation (3)); $v$ the molar volume (amorphous state/crystalline state), and $\rho$ the scattering length density. Ph stands for an aromatic cycle especially those present in the polyMDI shown in Figure 1.

\begin{tabular}{lcccc}
\hline E.S. & $Z$ & $v\left[\mathrm{~cm}^{3} \mathrm{~mol}^{-1}\right]$ & $a\left[\mathrm{fm}=10^{-13} \mathrm{~cm}\right]$ & $\rho\left[10^{10} \mathrm{~cm}^{-2}\right]$ \\
\hline$-\mathrm{CH}_{2}-\mathrm{CH}_{2}-\mathrm{O}-$ & 24 & $36.74 / 33.36$ & 67.68 & $11.09 / 12.22$ \\
$-\mathrm{CH}_{2}-\mathrm{CH}\left(\mathrm{CH}_{3}\right)-\mathrm{O}-$ & 32 & $53.09 / 48.03$ & 90.24 & $10.24 / 11.31$ \\
$-\mathrm{Ph}-\mathrm{CH}_{2}-\mathrm{Ph}-$ & 88 & $147.37 / 132.68$ & 248.16 & $10.14 / 11.26$ \\
$-\mathrm{CONH}-$ & 22 & 21 & 62.04 & 17.79 \\
$-\mathrm{OCONH}-$ & 30 & 29 & 84.60 & 17.57 \\
$-\mathrm{CONH}-\mathrm{Ph}-\mathrm{CH}_{2}-\mathrm{Ph}-\mathrm{NHOCO}-$ & 140 & $197.37 / 177.38$ & 394.80 & $12.05 / 13.40$ \\
\hline
\end{tabular}




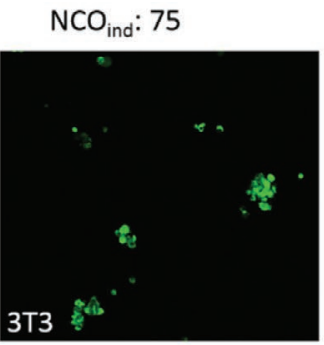

$\mathrm{NCO}_{\text {ind }}: 100$
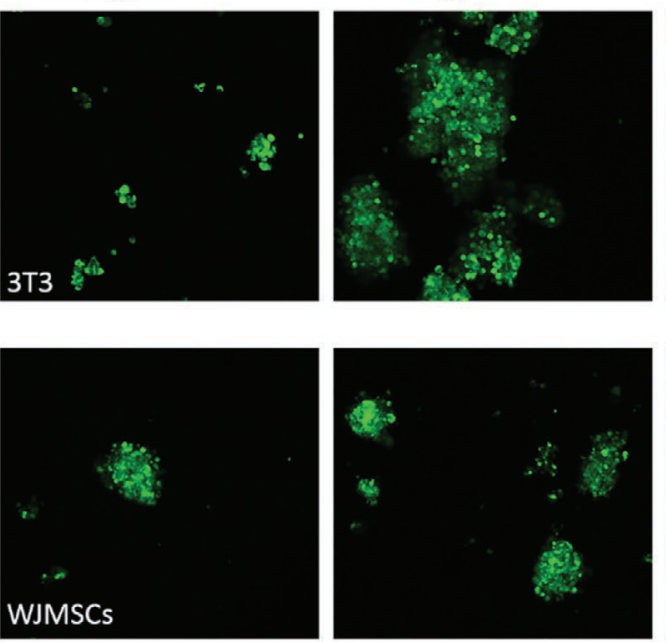

$\mathrm{NCO}_{\text {ind }}: 200$
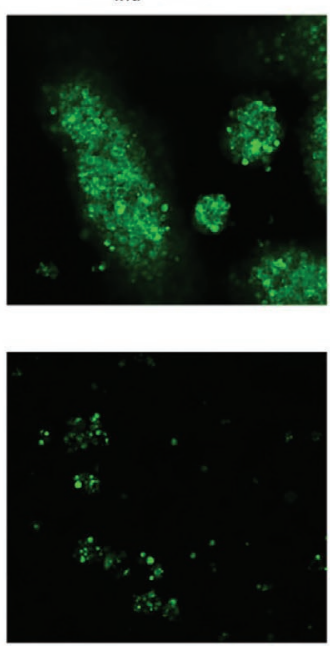

$\mathrm{NCO}_{\text {ind }}: 300$
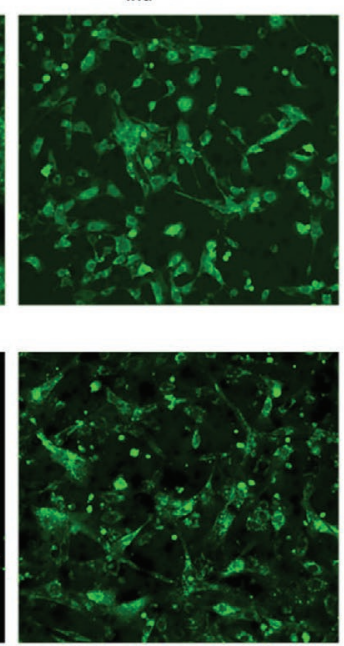

$\mathrm{NCO}_{\text {ind }}: 400$

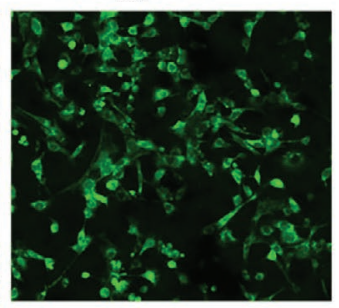

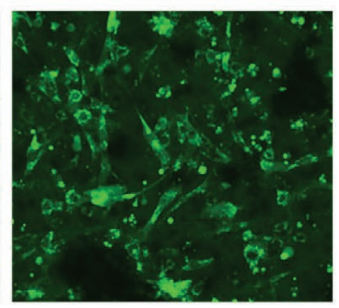

$100 \mu \mathrm{m}$

Figure 2. $3 T 3$ fibroblasts (top row) and WJMSCs (bottom row) seeded on PU films with various isocyanate indexes after $24 \mathrm{~h}$, cells were stained with Calcein-green.

\section{Results}

In order to see the effect of $\mathrm{NCO}_{\text {ind }}$ on cell adhesion, two types of cells were seeded on the substrates with different $\mathrm{NCO}_{\text {ind }}$ as shown in Figure 2. Both 3T3 fibroblasts and WJMSCs adhesion show a clear dependence on the $\mathrm{NCO}_{\text {ind }}$. A surface which is efficient to promote cellular adhesion results in a cell morphology where cells cover the surface and show a spindle like morphology. A threshold value seems to appear between $\mathrm{NCO}_{\text {ind }}=$ 200 and $\mathrm{NCO}_{\text {ind }}=300$ for cellular adhesion strength. For PU films having $\mathrm{NCO}_{\text {ind }}<200$, cells have a round shape and aggregate. Starting from $\mathrm{NCO}_{\text {ind }}=300$, cells can clearly spread on the substrate which indicates that they are able to adhere on the material surface. This demonstrates that cell adhesion on PU films was greatly affected by the $\mathrm{NCO}_{\text {ind }}$. From Figure 2, one can also notice that the threshold value in the $\mathrm{NCO}_{\text {ind }}$ seems to be the same for both cell types.

Then, cells were also fixed in paraformaldehyde and stained for F-actin filaments and nucleus by using DAPI/Phalloidin (see Section 2.5 for experimental details) and monitored with confocal microscopy. Obviously the same trend is emerging (Figure S1, Supporting Information) for PU films having an $\mathrm{NCO}_{\text {ind }}>$ 200: we can observe again that both cell types can spread on the surface, whereas no more cells can be observed on substrate with $\mathrm{NCO}_{\text {ind }}$ lower than 300 implying that the cellular adhesion depends on the PU formulation.

Cell adhesion on artificial substrates is a protein-mediated process. The physico-chemical properties of the substrate can induce conformational changes of the adsorbed proteins or discriminate one given type of protein with respect to another implying a surface concentration that differs from the concentration in the media.

In order to see whether this difference in cell spreading originates from differential cytotoxicity of PU films with different $\mathrm{NCO}_{\text {ind }}$, we first tested the cytotoxicity of the samples via an indirect contact method to investigate the effect potentially harmful products on the cells. For an implantable material to be authorized to be used in the human body, they should have a cell viability of at least $70 \%$ after direct or indirect contact with the material. For all the tested samples (i.e., $\mathrm{NCO}_{\text {ind }}$ of 75, 100, and 400) no cytotoxic effect was observed since the cell viability was always higher than $70 \%$ after normalization by the control (Figure S2, Supporting Information).

The response of the cells to $\mathrm{PU}$ films with various $\mathrm{NCO}_{\text {ind }}$ can be extrapolated to 3D structures. We prepared interconnected porous materials (as described in Section 2.2) with different $\mathrm{NCO}_{\text {ind }}$ into which we seeded WJMSCs. Details on the scaffold production and the cell culture are published elsewhere. ${ }^{[17]}$ We kept the same porous structure, using a $\mathrm{PU}$ that was synthesized with two different $\mathrm{NCO}_{\text {ind }}$ showing opposite cell adhesion when on films: $\mathrm{NCO}_{\text {ind }}=100$ which prevents cell adhesion and $\mathrm{NCO}_{\text {ind }}=400$ which promotes cell attachment. We seeded only WJMSC cells because the cell response to the $\mathrm{NCO}_{\text {ind }}$ was the same for both 3T3 and WJMSCs. Figure 3 shows that in the case of $\mathrm{NCO}_{\text {ind }}$ of 400 , groups of cells spread well within the pores of the scaffold whereas in samples with an $\mathrm{NCO}_{\text {ind }} 100$ nearly no cells were observed after 7 days. As for the adhesion on flat substrates, one thus observes that cell colonization in $3 \mathrm{D}$ is also facilitated in scaffolds made by $\mathrm{PU}$ with an $\mathrm{NCO}_{\text {ind }}$ of $400 \mathrm{com}$ pared to 100 .

Since the attachment of cells to a surface is often mediated by protein adsorption, we examined if the amount of adsorbed proteins depends on the $\mathrm{NCO}_{\text {ind }}$. We quantified the amount of proteins adsorbed onto the PU surface by two methods, namely the Bradford method and by recording the fluorescence intensity of FITC-BSA adsorbed on the PU surface (see Section 2.11) to ensure the reliability. We found that for samples having $\mathrm{NCO}_{\text {ind }}$ of 75 and 100, less proteins were adsorbed onto the PU surface (437 and $495 \mu \mathrm{g} \mathrm{mm}^{2}$ respectively) compared 

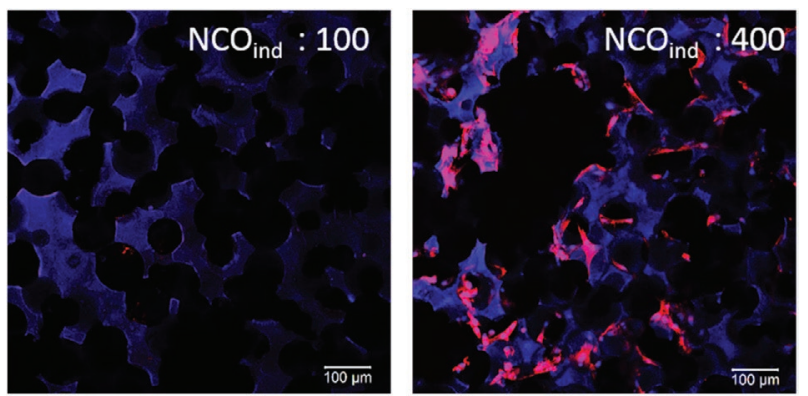

Figure 3. Images of WJMSC cells after 7 days of cell culture in a PU scaffold having an $\mathrm{NCO}_{\text {ind }}$ of 100 (left) and 400 (right). Cells were stained with DAPI/Phalloidin for the visualization of F-actin filaments and nucleus respectively.

to samples with $\mathrm{NCO}_{\text {ind }}$ higher than 200 whose adsorbed protein amounts are 758, 712 and $680 \mu \mathrm{g} \mathrm{mm} \mathrm{m}^{2}$ for $\mathrm{NCO}_{\text {ind }}$ of 200 , 300 , and 400 respectively (Figure S3, Supporting Information). But even if less protein adsorb onto the substrate with 75 and $100 \mathrm{NCO}_{\text {ind }}$, this cannot explain alone why cell adhesion seems prohibited on these films. Indeed, the amount of adsorbed proteins on samples with $\mathrm{NCO}_{\text {ind }} 200$ is at the same level as that of samples with $\mathrm{NCO}_{\text {ind }}$ of 300 and 400 yet, cells were not able to adhere the sample with $\mathrm{NCO}_{\text {ind }}$ of 200 .

To understand how the changes in isocyanate content can affect PU properties, and subsequently the adhesion capacity of the cells, we investigated the mechanical properties of the samples. To this end, tensile tests were performed on 1-mmthick PU films of variable $\mathrm{NCO}_{\text {ind }}$. Typical stress-strain curves are shown in Figure 4a. Curves are shown until rupture of the PU film. For all $\mathrm{NCO}_{\text {ind }}$, they show a nearly linear stress-strain dependence until rupture. As the isocyanate index increases, the initial slope of strain versus stress increases as well. Hence, the Young's modulus, which is given by this slope, increases with the amount of isocyanate used in the formulation. This is a well-known effect, since hard segments contribute to make the polymer stiffer. ${ }^{[2]}$ The obtained Young's moduli and the elongation at break are summarized in Figure 4b. For an isocyanate index of 75, the Young's modulus was $0.2 \mathrm{MPa}$ while it was $8 \mathrm{MPa}$ for $\mathrm{NCO}_{\text {ind }}$ of 400 . The Young's modulus increases significantly (nearly linearly) with isocyanate content until an $\mathrm{NCO}_{\text {ind }}$ of 300 . Above this value the increase in modulus with $\mathrm{NCO}_{\text {ind }}$ is less pronounced but as we only have one data point above the $\mathrm{NCO}_{\text {ind }}$ : 300 , we cannot conclude that this is a general trend. Therefore, cells start to adhere on PU films with Young's moduli around $8 \mathrm{MPa}$. Nevertheless, care must be taken to not hurriedly correlate those values to the ability of cells to sense the substrate stiffness. Indeed, the range of Young's moduli in substrate stiffness to which cells are sensitive is commonly between tens to hundreds of $\mathrm{kPa}^{[28]}$ which are significantly smaller than the Young's moduli measured for all our samples. Therefore, we hypothesize that for films having Young's moduli above $0.7 \mathrm{MPa}$, cells are not sensitive to the averaged modulus that is measured by the mechanical testing but rather to the more local material properties. It is also noteworthy that the elongation at break decreases with increasing $\mathrm{NCO}_{\text {ind }}$ (Figure $4 \mathrm{~b}$ ). For the lowest index (i.e., $\left.\mathrm{NCO}_{\text {ind }}: 75\right)$, the elongation at break is $73 \%$ compared to $24 \%$ for $\mathrm{NCO}_{\text {ind }}$ of 400 .
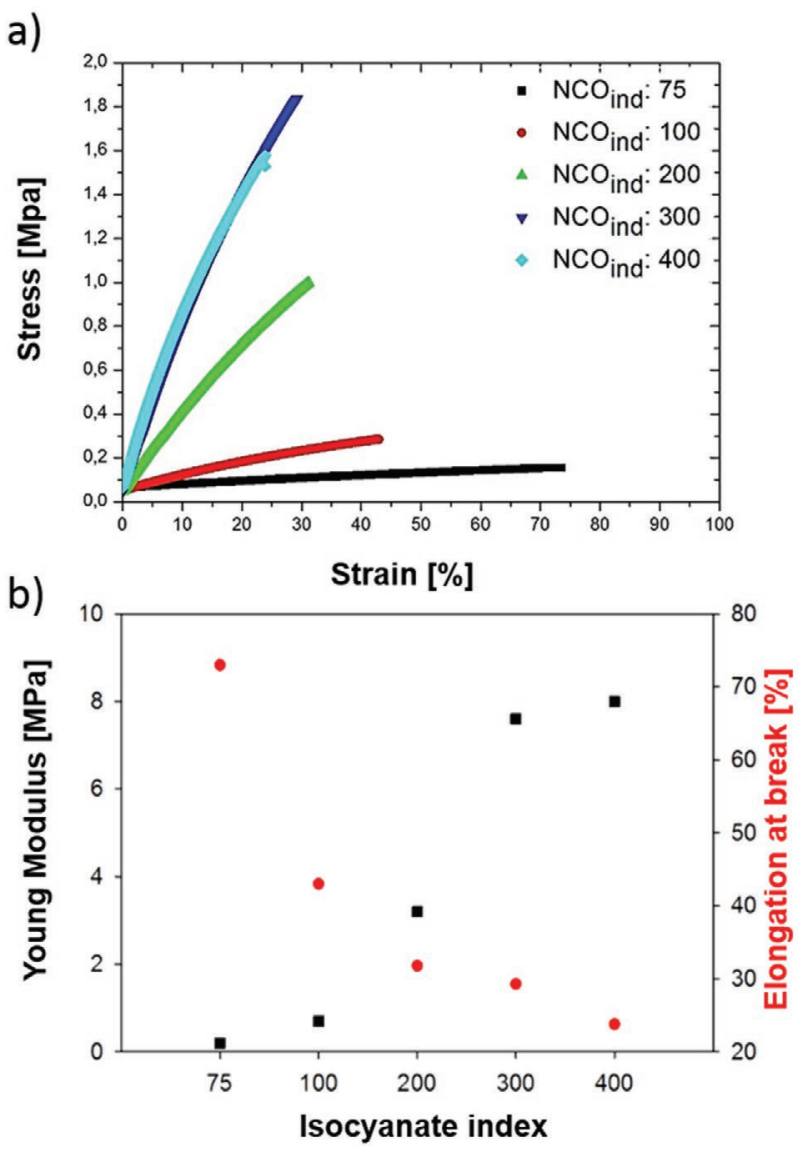

Figure 4. a) Stress-strain curve of polyurethane films obtained upon stretching and b) their corresponding Young's modulus and elongation at break (red plots).

These differences can be explained by the increased crosslink density with increasing $\mathrm{NCO}_{\text {ind }}$. Therefore, variation of the $\mathrm{NCO} / \mathrm{OH}$ functions in the formulation of polyurethane allows adjusting finely the mechanical properties, ${ }^{[29]}$ but these changes cannot be considered as the main driving factor in the difference in cell behavior.

Infrared spectroscopy was also employed to investigate the differences in chemical functions for the different samples. The FTIR spectra obtained for PUs with increasing $\mathrm{NCO}_{\text {ind }}$ are shown in Figure 5. An increase in the NCO content of the polymer shows an increase in the intensity of the band at 2274 $\mathrm{cm}^{-1}$ associated with free NCO groups ${ }^{[22]}$ as well as an increase of the bands at 1597 and $1411 \mathrm{~cm}^{-1}$ which are attributed to aromatic and isocyanurate vibrations respectively. Peaks at 1539 and $1727 \mathrm{~cm}^{-1}$ correspond to amide I and II respectively. ${ }^{[30]}$ On Figure $5 \mathrm{a}$, one can clearly see that peaks associated to free $\mathrm{NCO}$ groups increase with increasing $\mathrm{NCO}_{\text {ind }}$. This is rather obvious since unreacted isocyanate functions remain left for $\mathrm{NCO}_{\text {ind }}$ greater than 100 . However, due to the highly reactive nature of isocyanate, free $\mathrm{NCO}_{\text {ind }}$ tend to react with other free $\mathrm{NCO}$ groups to form isocyanurates which are indeed present by looking at the band at $2274 \mathrm{~cm}^{-1}$ (Figure 5b). Additionally, NCO groups are also known to be able to react with primary and secondary amines. ${ }^{[31]}$ Urea, biuret, or allophanates 


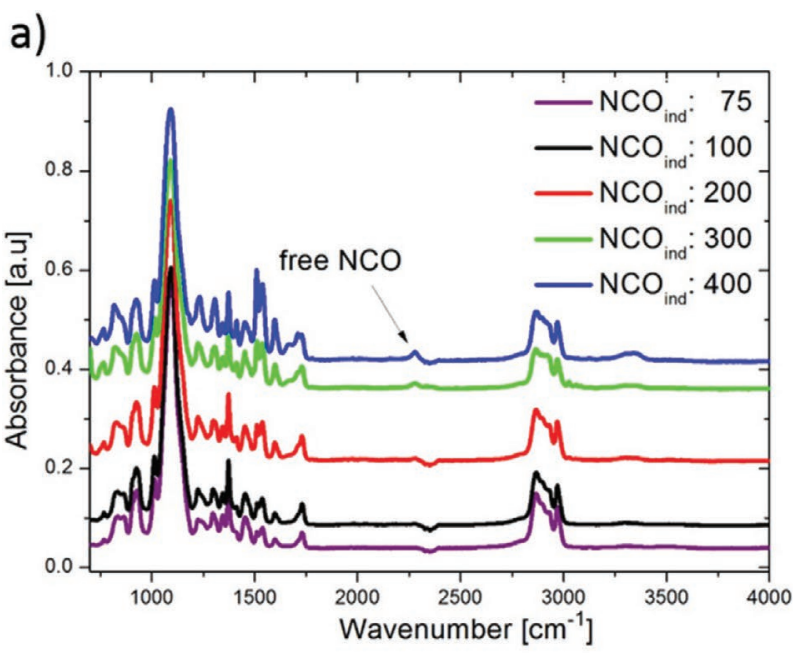

b)

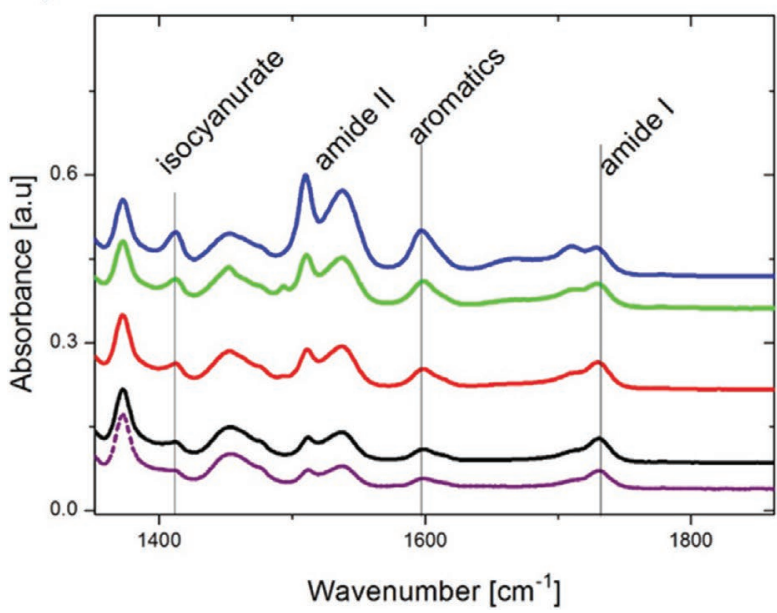

Figure 5. a) FTIR spectra of PU films with various $\mathrm{NCO}_{\text {ind }}$ and b) a higher magnification of the region between 1350 and $1850 \mathrm{~cm}^{-1}$.

are common products of these reactions. ${ }^{[31]}$ These side products are associated to the peaks at 1539 and $1727 \mathrm{~cm}^{-1}$ corresponding to amide $\mathrm{I}$ and II vibrations respectively. In Figure 5b, the curves for $\mathrm{NCO}_{\text {ind }} 75$ and 100 show the same profile whereas, for higher indexes, all the peaks associated to species that result from the reaction of free isocyanates groups are increasing.

To gain more insight into the process by which cells can adhere to the PU surface, one needs to characterize the outermost surface of the considered material. It is well known that the surface chemistry of polyurethanes tends to be different from the bulk composition. ${ }^{[32]}$ Hence, X-Ray Photoelectron Spectroscopy (XPS) analyses were carried out to evaluate what are the changes induced by these specific $\mathrm{NCO}_{\text {ind }}$ on surface chemistry.

The respective peaks of the $\mathrm{O}_{1 \mathrm{~S}}, \mathrm{C}_{1 \mathrm{~S}}$, and $\mathrm{N}_{1 \mathrm{~S}}$ orbitals are shown in Figure 6a,b,d. We were not able to obtain the spectra of the sample with an $\mathrm{NCO}_{\text {ind }}$ of 75 because the ultrahigh vacuum could not be achieved. This could be due to unreacted monomers that leached out of the sample. Peaks at 284.6 and $286.5 \mathrm{eV}$ on the $\mathrm{C}_{1 \mathrm{~S}}$ spectra are attributed to aliphatic carbons and carbons from $\mathrm{C}-\mathrm{O}-\mathrm{C}$ ether functions respectively. ${ }^{[33]}$ The peak at $400 \mathrm{eV}$ on the $\mathrm{N}_{1 \mathrm{~S}}$ nitrogen curve (Figure $6 \mathrm{~b}$ ) corresponds to nitrogen atoms in the urethane and/or urea bonds. ${ }^{[11]}$ Interestingly, when the $\mathrm{NCO}_{\text {ind }}$ increases, the nitrogen percentage at the surface does almost not vary for $\mathrm{NCO}_{\text {ind }}$ of 100,200 , and 300 where values are comprised between $0.3 \%$ and $0.6 \%$. Nitrogen content increases more for $\mathrm{NCO}_{\text {ind }} 400$ to reach $1.9 \%$. As nitrogen is only present on hard segments, one can use the nitrogen quantification as an indication of the amount of hard segments at the topmost surface of the PU. These findings are in good agreement with other studies which demonstrated that hard segment content at PU surface remains fairly constant. ${ }^{[34,35]}$ One generally accepted explanation is that PU outermost surface is enriched in soft segments to lower the surface energy. ${ }^{[36,37]}$ The higher nitrogen percentage in the sample with an $\mathrm{NCO}_{\text {ind }}$ of 400 is consistent with the study of Nakamae et al. ${ }^{[36]}$ who also observed that hard segments are more present at the surface when their concentration is increased. However, XPS analysis is performed under high vacuum, and these conditions are not necessarily accurate to describe the surface in aqueous media. Nevertheless, XPS measurements allow us to identify the chemical species formed in the PU. Of particular interest is the spectrum associated to nitrogen which is never shifted. This implies that the side products formed by the reaction of free isocyanate with other groups than hydroxyl are not present at the topmost surface of the samples.

We also performed contact angle measurements of water drops deposited on the PU surfaces (Figure 7). Contact angles progressively increase from $48^{\circ}$ to $96^{\circ}$ with increasing $\mathrm{NCO}_{\text {ind }}$ up to an $\mathrm{NCO}_{\text {ind }}$ of 300 , that is, the samples are becoming increasingly hydrophobic. Beyond this value, the contact angle seems constant at $100^{\circ}$. Since the only parameter that was varied is the ratio of isocyanate to hydroxyl function in the PU synthesis, differences in contact angle values can be correlated to changes in isocyanate content from one sample to another. Furthermore, aromatic rings, being hydrophobic compound, contained in the polyMDI are assumed to contribute to the enhanced hydrophobicity. This appears contradictory with the XPS analysis where surface chemistry was shown to be the same regardless of the $\mathrm{NCO}_{\text {ind }}$. One can therefore assume that surface rearrangement at the PU/water interface differs from the PU/air interface.

Surface roughness was also investigated by AFM measurement (Table S1, Supporting Information). The root mean square values show a maximum at $12.9 \mathrm{~nm}$ for an $\mathrm{NCO}_{\text {ind }}$ of 75 and $1.6 \mathrm{~nm}$ for an $\mathrm{NCO}_{\text {ind }}$ of 400 . Therefore, the contact angle value can depend on both differences in surface chemistry and on surface roughness.

We also investigated the microscopic structure of the PU films using both WAXS/SAXS methods. Figure 8a shows the combined results from both techniques. The region corresponding to WAXS (i.e., for $q>0.3 \AA^{-1}$ ) displays a unique and similar halo for every sample indicating an amorphous system. Indeed, no Bragg peak appears in this q-range for any of the $\mathrm{NCO}_{\text {ind }}$, indicating the absence of measurable crystalline 


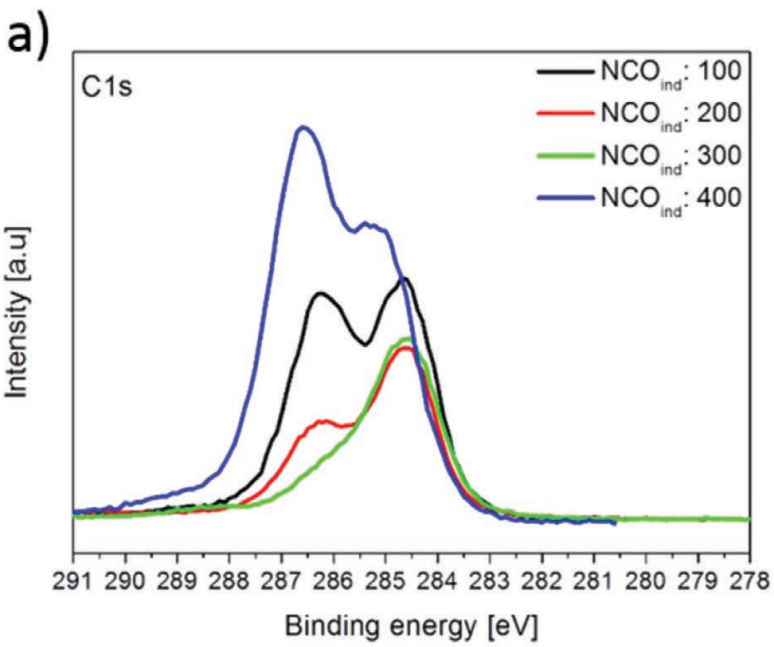

c)

\begin{tabular}{cccc}
\hline sample & \%C & \%O & \%N \\
\hline $\mathrm{NCO}_{\text {ind }} 100$ & 75.8 & 22.2 & 0.6 \\
$\mathrm{NCO}_{\text {ind }} 200$ & 80.4 & 18.8 & 0.3 \\
$\mathrm{NCO}_{\text {ind }} 300$ & 84.0 & 15.3 & 0.6 \\
$\mathrm{NCO}_{\text {ind }} 400$ & 72.2 & 25.0 & 1.9
\end{tabular}

b)

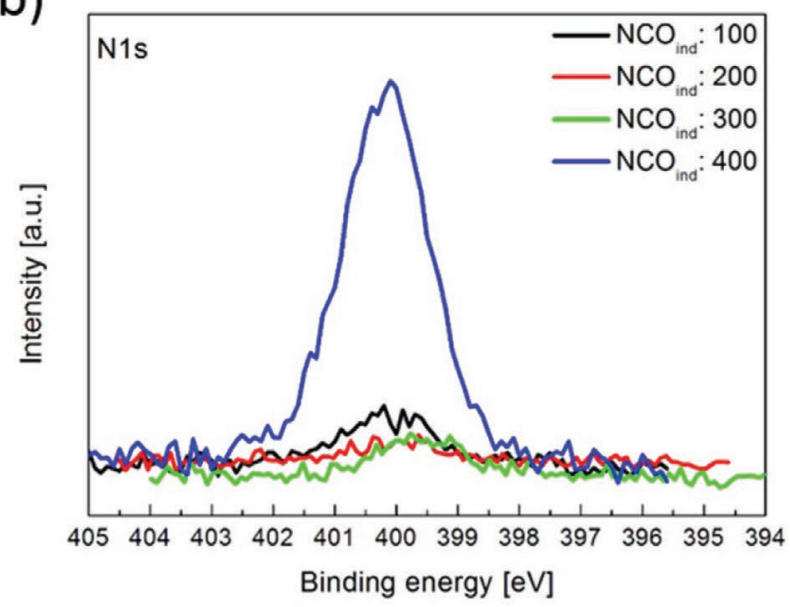

d)

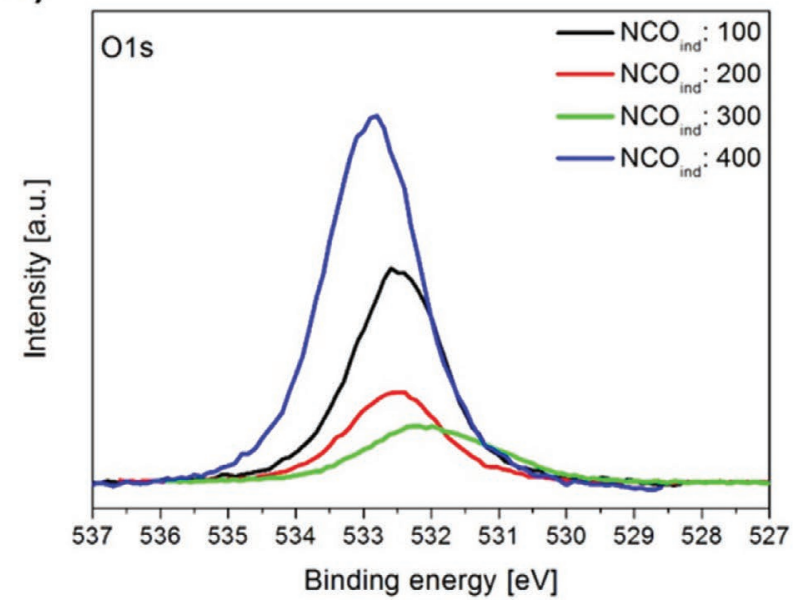

Figure 6. XPS spectra of PU film surfaces at energies corresponding to orbitals a) $C_{1 s}$, b) $N_{1 s}$, d) $O_{1 s}$, and c) their elemental composition.

structures. This can be explained by the steric hindrance of PPO chains and the oligomeric nature of polyMDI compared to its monomeric form MDI which is known to be able to crystallize. ${ }^{[38]}$

From the SAXS measurements (i.e., for $q<0.3 \AA^{-1}$ ) shown in Figure 8a a clear evidence of micro phase separation can be observed as attested by the peaks around $0.08 \AA^{-1}$. This can be interpreted as a result of the presence of small domains separated by $7.7 \mathrm{~nm}\left(\mathrm{NCO}_{\text {ind }}: 75\right)$ and $7.9 \mathrm{~nm}\left(\mathrm{NCO}_{\text {ind }}\right.$ : 400$)$ respectively which is quite similar. We interpret this as the signature of hard domains embedded in soft matrix. ${ }^{[39,40]}$ The peak intensity increases with increasing $\mathrm{NCO}_{\text {ind }}$. No second- or third-order peaks are visible, ruling out the possibility that hard domains display translational order within the soft segments matrix. If the interface between the hard and soft domains was sharp, one would expect a decrease of the tail of the curve for small angles (i.e., $q<0.3 \AA^{-1}$ ) proportional to $q^{-4}$ according to Porod law. ${ }^{[41]}$ Hence, in such conditions one can use the Porod's invariant ${ }^{[41]}$ $Q$ defined as
$Q=\frac{1}{2 \pi^{2}} \int_{0}^{\infty} q^{2} I(q) \mathrm{d} q$

and

$Q=\Delta \rho^{2} \phi_{s} \phi_{h}=\Delta \rho^{2} \phi_{s}\left(1-\phi_{s}\right)$

where $q$ is the scattering vector, $\phi_{\mathrm{s}}$ and $\phi_{\mathrm{h}}$ are the volume fraction of the soft and hard domains, respectively, and $\Delta \rho^{2}=\left(\rho_{s}-\rho_{h}\right)^{2}$ is the square of the difference of the scattering length density of the electrons between hard and soft domains. We do not observe this slope because the peak associated with the density fluctuations at $1.5 \AA^{-1}$ starts very close to the peaks associated with the phase separation. Therefore, we suppose that the contribution of the second peak at large angles $\left(q \approx 0.076-\AA^{-1}\right)$ may overlap the peak associated with the phase separation. However, by subtracting the contribution of the density fluctuations (see Section 2.15), one obtains 


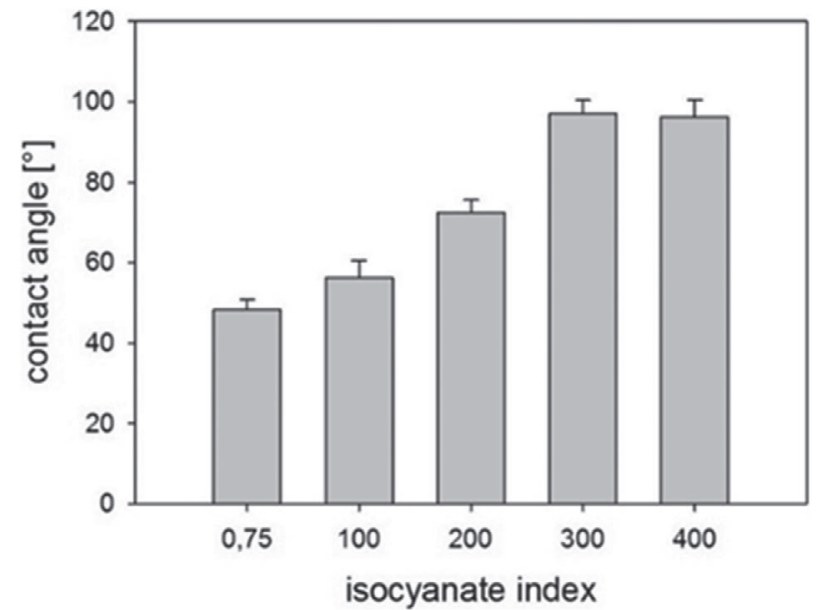

Figure 7. Static contact angle measurement of ultrapure water for PU films with various $\mathrm{NCO}_{\text {ind. }}$.

curves in which the tail of the SAXS region is decreasing as $q^{-4}$ since

$\lim _{q \rightarrow \infty} I(q)=2 \pi \Delta \rho^{2} \frac{S}{V} \frac{1}{q^{4}}$

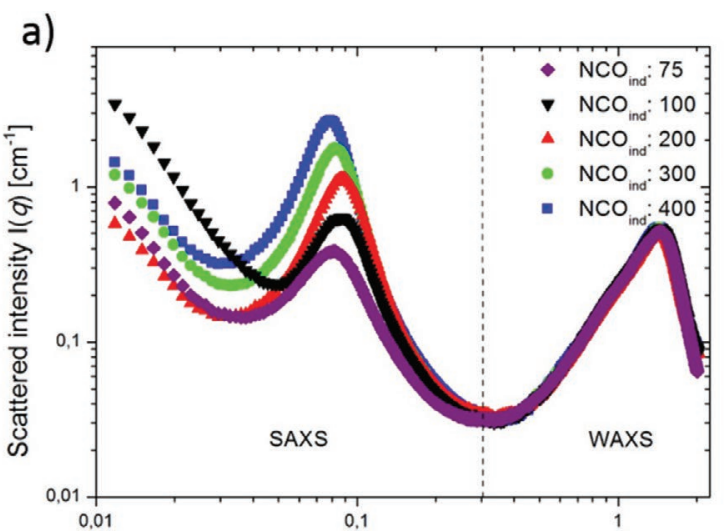

b)

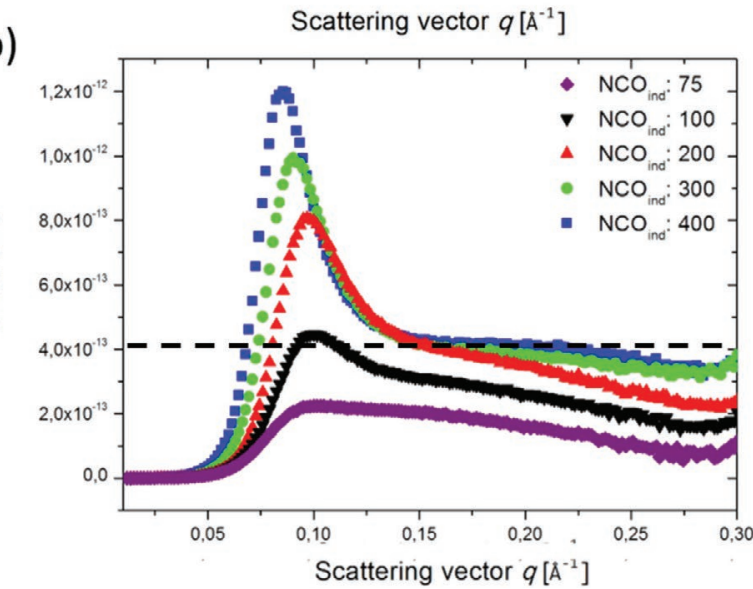

Figure 8. Evolution of the scattered intensity (log scale) measured by SAXS/WAXS for PU samples with various $\mathrm{NCO}_{\text {ind }}$ a) the dashed line indicates the SAXS/WAXS transition. b) Porod representation for the different samples, the dashed line indicates the plateau. where $S / V$ is the total area of the interfaces divided by the total volume of the sample. By plotting $q^{4} I(q)$ as a function of $q$ (Figure $8 \mathrm{~b}$ ), one should therefore obtain a plateau for the $q$ values $>q_{\text {peaks }}$ when the two phases are separate by sharp interfaces. This plateau is observed for samples having an $\mathrm{NCO}_{\text {ind }}$ of 300 and 400 , as seen in Figure $8 \mathrm{~b}$. This plateau starts at $q \approx 0.15 \AA^{-1}$ and is quite short.

Even samples with $\mathrm{NCO}_{\text {ind }}$ of 300 and 400 show a decrease of their respective $q^{4} I(q)$ versus $q$ curves at a given point around $0.22 \AA$. This means that some diffuse interfaces are also present within these systems but to a much lower extend. According to Buckley et al., ${ }^{[42]}$ interfaces are diffuse when hard and soft segments are interpenetrating and the separation between hard and soft domains is not sharp anymore. For diffuse interfaces, the evolution of the tail of the curves of $I(q)$ obeys the following law ${ }^{[43]}$

$\lim _{q \rightarrow \infty} q^{4} I(q)=2 \pi \Delta \rho^{2} \frac{S}{V} \exp \left(-q^{2} \sigma^{2}\right)$

or,

$\lim _{q \rightarrow \infty} \ln \left[\mathrm{q}^{4} I(q)\right]=\ln \left[2 \pi \Delta \rho^{2} \frac{S}{V}\right]-q^{2} \sigma^{2}$

where $\sigma$ is related the average width $l$ lof the diffuse interface $l$ between the hard and soft domains by $l=\sqrt{2 \pi \sigma}$ when using a model describing a sigmoidal interface. ${ }^{[44]}$ From Equation (9), by plotting $\ln \left[q^{4} I(q)\right]$ as a function of $q^{2}$ (Figure 9), we obtain curves whose slope is related to the width of the diffuse interface. As seen in Figure 9, the width of the interface increases with decreasing $\mathrm{NCO}_{\text {ind }}$. This is in accordance with our observations in Figure 8 since samples with $\mathrm{NCO}_{\text {ind }}$ of 300 and 400 display a plateau consistent with a sharp interface. We find that the width of the interface of these two samples is $l=3.8$ and 5.3 $\AA$ respectively. Samples with lower $\mathrm{NCO}_{\text {ind }}$ have a more diffuse interface whose thickness increases from $7.6 \AA\left(\mathrm{NCO}_{\text {ind }}: 300\right)$ to $9.9 \AA\left(\mathrm{NCO}_{\text {ind }}: 75\right)$.

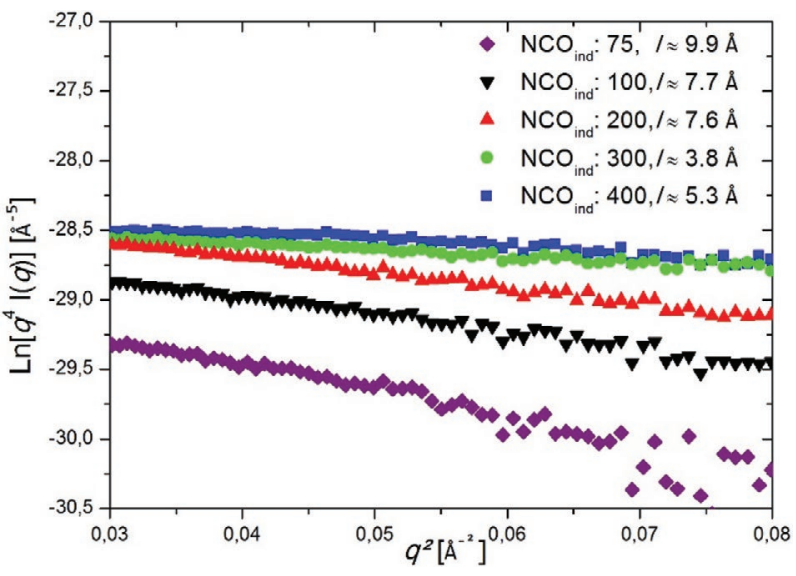

Figure 9. Evolution of $\ln \left[q^{4} I(q)\right]$ as a function of $q^{2}$ for samples with $\mathrm{NCO}_{\text {ind }}$ of 75 to 400 . The slope of each curves provides the square width $l^{2}$ of the diffuse interface, the calculated width $l$ is provided in the caption for each sample. 
From the knowledge of the height of the plateau in Figure 8 , one can determine the total surface area $S$ of the interfaces divided by the volume of the sample $V$. Moreover, from the product of volume fractions of hard and soft segments $\phi_{\mathrm{s}} \phi_{\mathrm{h}}$ used in the batch (Supporting Information) one can estimate the Porod inhomogeneities length $l_{p}$ (see Equation (S2), Supporting Information) which correspond to an average radius of the domains. We determined $l_{p}$ to be 2.7 and $2.3 \mathrm{~nm}$ for an $\mathrm{NCO}_{\text {ind }}$ of 400 and 300, respectively. The absence of a plateau for samples with $\mathrm{NCO}_{\text {ind }}$ below 300 prevents us from extracting an accurate value of $S / V$ from the curves in Figure 8; hence, no value for the radius of the domains in samples with $\mathrm{NCO}_{\text {ind }}$ below 300 can be provided in this study.

A schematic representation of the PU microstructure with sharp and diffuse interfaces is shown in Figure 10a,b.

Moreover, by integrating the curves $q^{2} I(q)$ versus $q$ (see Figure S4, Supporting Information) one can obtain the Porod invariant $Q$ expressed in Equation (5), and compare this value to the theoretical one $Q_{t}$ (see Table S2, Supporting information) obtained from the known volume fractions of both polyol and isocyanate added during synthesis and from $\Delta \rho^{2}$ in Table 1. One can then define a degree of phase separation which is the experimental $Q$-values of our samples expressed as percentage of the theoretical $Q_{t}$-values (system with purely sharp interfaces). We obtained respectively $81 \%$ and $82 \%$ for $\mathrm{NCO}_{\text {ind }}$ of 300 and 400 . This illustrates again that sharp interfaces coexist with diffuse interfaces, but the degree of phase separation is high enough to form domains. We hypothesize that it is these domains that support cell adhesion.

We have found that both cell types, 3T3 and WJMSCs, could adhere on PU surface that exhibits phase separation between hard and soft segments at the condition that the hard/soft segment interface is sharp. Conversely, PU, whose hard/soft segments interface is diffuse, do not promote cell attachment. These findings are summarized in Figure 10. For samples a)

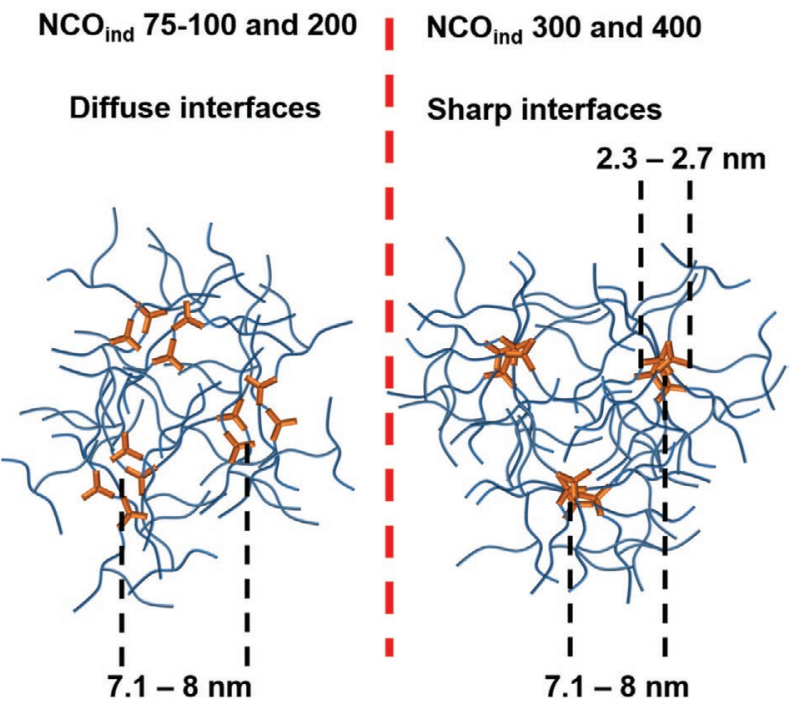

Figure 10. Schematic representation of PU structure with phase separation when the interface between hard and soft segments is a) diffuse and b) sharp. with $\mathrm{NCO}_{\text {ind }}$ of 300 and 400 , we estimated the size of the hard domains through Porod's law as 2.3 to $2.7 \mathrm{~nm}$ for $\mathrm{NCO}_{\text {ind }}$ of 300 and 400 respectively. The interdomain distance was determined by the position of the peaks in the SAXS curve Figure 8a and we found values between 7.1 and $8 \mathrm{~nm}$ without clear trend between the $\mathrm{NCO}_{\text {ind }}$.

\section{Discussion}

The adhesion of cells on a synthetic substrate is not straightforward since these materials lack the binding motifs that are found in the extracellular matrix (ECM). The use of surface modifications or coatings is widespread to improve the surface bioactivity regarding cell behavior inside the body or in vitro. Such approaches tend to be time-consuming (covalent immobilization), and costly (addition of specific ECM molecules), sometimes temporary (plasma treatment ${ }^{[17]}$ ) and rarely highly efficient (due to stability issue, detachment etc.) which hamper their applications in the medical domain. However, some synthetic materials can promote cell adhesion and subsequently support cell proliferation. The understanding of the intrinsic properties of such materials is important for applications in regenerative medicine or tissue engineering. We propose here a simple way to modulate the adhesion of both WJMSCs and 3T3 fibroblasts by tailoring the isocyanate index of PUs. In particular, we show that a clear threshold exists in the isocyanate index beyond which both cells types adhere easily on the surface. As the first glance, one may expect that for $\mathrm{NCO}_{\text {ind }}$ below 100, the excess of hydroxyl groups would render the material more hydrophilic and thus increase the cellular adhesion. Indeed, several studies report that hydrophilic surfaces are more likely to allow cell attachment, ${ }^{[45]}$ but the correlation between contact angle values and the cellular adhesion is not established in a material dependent manner yet. ${ }^{[46]}$ Here we showed that the more hydrophobic surfaces (i.e., $\mathrm{NCO}_{\text {ind }}$ of 300 and 400) allow both cell types to adhere on our PU films. Cell adhesion appears at a threshold value of the $\mathrm{NCO}_{\text {ind }}$ between 200 and 300. As the interaction of cells with the substrate is directed by the outermost surface, we evaluated the changes in surface chemistry associated with changes in $\mathrm{NCO}_{\text {ind }}$.

As shown in our XPS measurements (Figure 6), chemical species are the same for all samples and the outmost layer is enriched in soft segments. This is consistent with the studies of Hearn et al. ${ }^{[4]}$ who conclude that the difference in composition between the surface and the bulk material is due to surface rearrangements to minimize the surface energy. However, care must be taken in this assumption since XPS are conducted under ultra-high vacuum and these conditions cannot capture the "real" surface arrangement when samples are in aqueous conditions. Moreover, several other authors reported ${ }^{[48,49]}$ that the PU surface is a dynamic environment and that undergoes rearrangement that depend on the hydration time. Nevertheless, XPS study allowed to determine the chemical nature of the species generated in the PU.

Protein adsorption is also a key element that is the first step in the adhesion process. We showed that the amount of proteins adsorbed onto the material surface is nearly the same for all the samples except for the ones with lower $\mathrm{NCO}_{\text {ind }}(100$ and 75$)$. We 
expect that in these later cases some free ethylene glycol groups repel the adsorption of proteins. ${ }^{[50]}$ Nevertheless, samples with $\mathrm{NCO}_{\text {ind }}$ of 200,300 , and 400 have similar quantities of proteins adsorbed onto the PU substrate but cell do not adhere to PU with 200 as NCO index. Hence the modulation of cell adhesion cannot be explained by the argument of increased protein adsorption only.

The main hypothesis which we put forward here to explain the cell response with $\mathrm{NCO}_{\text {ind }}$ is related to the segmented structure of the polyurethane. It is well known that the polyurethane microstructure is well described as a biphasic system where hard segments form distinct domains scattered within a matrix of soft segments. ${ }^{[51]}$ This phase separation can be controlled by several parameters such as the molecular weight of polyols, ${ }^{[52]}$ the type of chain extender, ${ }^{[53]}$ or the amount of isocyanate used in the formulation. Hsu et al. ${ }^{[48]}$ demonstrated that phase separation in poly(carbonate urethane) is important to support endothelial cell adhesion and proliferation compared to PU where hard and soft segments are homogenously mixed and therefore do not form any domains. Therefore, when a PU surface displays clear nanodomains, cells may sense these heterogeneities and preferentially attach to these hard domains. Using WAXS and SAXS, we demonstrated that our PUs exhibit a phase separation for all our experimental conditions. Nalluri et al. ${ }^{[15]}$ showed that PU having hard segment domains separated with non-adherent PEG soft segment allowed for MSCs to spread and adhere on the surface on the contrary to PUs that do not exhibit any phase separation. The same trend was observed by Yuan et al. ${ }^{[14]}$ for endothelial cells. Furthermore, Hao et al. ${ }^{[16]}$ produced thermoplastic polyurethane and showed that 3T3 fibroblasts were able to adhere better on PU with high hard segment content than on those having smaller hard segment content. They also demonstrated that protein adsorption was higher when decreasing the amount of hard segments even though cells could not adhere on those surfaces.

We confirmed that phase separation in PU can be controlled by the $\mathrm{NCO}_{\text {ind }}$. We used SAXS and WAXS methods to analyze the degree of phase separation within the polymer and we demonstrate that even if phase separation is confirmed for all samples, the nature of phase separation between hard and soft segments is different. Our analysis shows that the existence of domains enriched with either hard or soft segments within the polymer is not enough to promote cellular adhesion, but that the "quality" of phase separation is the important feature. Using Porod's law, ${ }^{[43]}$ we showed that samples with $\mathrm{NCO}_{\text {ind }}$ of 300 and 400 display sharp interfaces, indicating a more complete phase separation. This is attested by the plateau in Figure $8 \mathrm{~b}$ which indicates that $I(q) \propto q^{-4}$ at the tail of the SAXS curve which is consistent with systems with sharp interfaces, and thus, more complete phase separation. ${ }^{[42,54]}$ On the other hand, samples with $\mathrm{NCO}_{\text {ind }}$ of 75, 100, and 200 exhibit a more pronounced decrease of the tail of the peak at small angles by looking at the curves in Figure $8 \mathrm{~b}$ which indicates that the interfaces between hard and soft segments are diffuse. Therefore, hard domains are not only composed of hard segments but also of soft segments that are interpenetrated. The dependence of the degree of phase separation on the $\mathrm{NCO}_{\text {ind }}$ was already shown by Saiani et al. ${ }^{[55]}$

Moreover, the isocyanate index is also contributing to the extent of phase separation within the system. When the degree of phase separation is high enough, interfaces are sharp, and the separation between hard and soft domains is clear. These domains form islets that could allow the cells to adhere on the surface. It was already demonstrated that for copolymers that undergo phase separation, the dispersed phase can be used as islet to allow cells to forms focal contacts while the continuous phase (non-adhesive) contributes to the overall mechanical properties of the polymer. ${ }^{[56]}$ Besides, the domains in this study are disorganized in space. This is, in fact, an advantage for cell adhesion as Dalby et al. ${ }^{[57]}$ demonstrated that randomly distributed nano pits are more likely to promote cell adhesion and MSCs osteogenesis compared to organized pit (i.e., in square and hexagonal).

The exact mechanism by which cells can be attached on PU surface via microdomains has yet to be elucidated. The wettability properties of a given material affect drastically protein adsorption and conformation as demonstrated by Tzoneva et al. ${ }^{[58]}$ Therefore, we hypothesize that microdomains induce conformational changes on the adsorbed proteins which in turn mediate cell adhesion which was also proposed by Groth et al. ${ }^{[59]}$ who showed that platelet adhesion on PU surface depend on hard segment content and probably on proteins conformation.

\section{Conclusion}

We generated polyurethane films with controlled $\mathrm{NCO}_{\text {ind }}$. We demonstrated that the cell attachment is linked with the $\mathrm{NCO}_{\text {ind }}$ and we showed that both 3T3 fibroblasts and WJMSCs were able to attach on the PU surfaces which have an $\mathrm{NCO}_{\text {ind }}$ higher than or equal to 300 . In order to understand the underlying reason for such differences regarding cell adhesion, we further characterized our substrates in terms of surface wettability, surface chemistry, Young's modulus, and structure properties. We demonstrated that the $\mathrm{NCO}_{\text {ind }}$ influences the degree of phase separation within the polymer. For $\mathrm{NCO}_{\text {ind }}$ of 300 and 400 , phase separation is more complete and interfaces are sharp whereas for $\mathrm{NCO}_{\text {ind }}$ below 300, the interfaces are diffuse. This implies that in this later case the hard domains are not only composed of hard segments but also contain a fraction of soft segments. This may explain why cells adhere only on PU with indexes higher than 300 since it is the hard domains that were already found to favor cell adhesion. We finally extrapolated these results from flat surfaces to a tridimensional scaffold. We showed that this cell adhesiveness is also maintained when cultured in $3 \mathrm{D}$ which is a promising way to combine a controlled microarchitecture of the scaffold with nano-cues to support cells adhesion for tissue engineering applications.

\section{Supporting Information}

Supporting Information is available from the Wiley Online Library or from the author.

\section{Acknowledgements}

The authors thank Christophe Contal for his AFM analysis as well as Geraldine Koenig for scientific discussions. The authors also thank Robin 
Bollache for technical support. The technical assistance from Dr. Vasiliki Papaefthimiou (ICPEES) was greatly appreciated. Moreover, Guillaume Fleith's help for diffusion experiments was also highly appreciated and the authors thank him for that. The authors also thank FoamPartner for having supplied reactants. This work has been published within the IdEx Unistra framework (Chaire W. Drenckhan) and has, as such, benefited from funding from the state, managed by the French National Research Agency as part of the "Investments for the future" program. The work was also supported by the Institut Carnot MICA (project DiaArt) and by an ERC Consolidator Grant (agreement 819511 - METAFOAM). The authors thank Horizon 2020 PANBioRA (Grant agreement No 760921) as well as the grant of doctoral school of physics and physical chemistry of Strasbourg $(\mathrm{GL})$.

\section{Conflict of Interest}

The authors declare no conflict of interest.

\section{Keywords}

hard segments, isocyanate index, phase separation, polyurethane, wharton's jelly mesenchymal stem cells

Received: February 11, 2020

Published online: March 20, 2020

[1] R. O. Hynes, Cell 1992, 69, 11.

[2] M. H. Sonntag, J. Schill, L. Brunsveld, ChemBioChem 2017, 18, 441.

[3] U. Hersel, C. Dahmen, H. Kessler, Biomaterials 2003, 24, 4385.

[4] C. J. Wilson, R. E. Clegg, D. I. Leavesley, M. J. Pearcy, Tissue Eng. 2005, 11, 1 .

[5] K. S. Siow, L. Britcher, S. Kumar, H. J. Griesser, Plasma Processes Polym. 2006, 3, 392.

[6] S. A. Guelcher, Tissue Eng., Part B 2008, 14, 3.

[7] P. Vermette, H. J. Griesser, G. Laroche, R. Guidoin, Biomed. Applicat. Polyurethanes, Landes Bioscience, Georgetown, TX 2001.

[8] Y.-K. Jhon, I.-W. Cheong, J.-H. Kim, Colloids Surf. A 2001, 179, 71.

[9] H. S. Lee, S. L. Hsu, Macromolecules 1989, 22, 1100.

[10] S. Abouzahr, G. L. Wilkes, J. Appl. Polym. Sci. 1984, 29, 2695.

[11] B. J. Tyler, B. D. Ratner, D. G. Castner, D. Briggs, J. Biomed. Mater. Res. 1992, 26, 273.

[12] Y. Li, T. Gao, B. Chu, Macromolecules 1992, 25, 1737.

[13] H. N. Ng, A. E. Allegrezza, R. W. Seymour, S. L. Cooper, Polymer. 1973, 14, 255

[14] Y. Yuan, C. Cheah, A. Arzumand, J. Luo, G. R. Krishnan, D. Sarkar, Technology 2016, 04, 139.

[15] S. M. Nalluri, G. R. Krishnan, C. Cheah, A. Arzumand, Y. Yuan, C. A. Richardson, S. Yang, D. Sarkar, Mater. Sci. Eng. C. 2015, 54, 182.

[16] H.-Y. Mi, X. Jing, M. R. Salick, T. M. Cordie, X.-F. Peng, L.-S. Turng, J. Biomed. Mater. Res., Part B 2015, 103, 960.

[17] G. Lutzweiler, J. Barthès, G. Koenig, H. Kerdjoudj, J. Mayingi, F. Boulmedais, P. Schaaf, W. Drenckhan, N. E. Vrana, ACS Appl. Mater. Interfaces 2019, 11, 19819.

[18] W. K. Nichols, D. Gospodarowicz, T. R. Kessler, D. B. Olsen, ASAIO J. 1981, 27, 208.

[19] H.-B. Lin, W. Sun, D. F. Mosher, C. Garcia-Echeverria, K. Schaufelberger, P. I. Lelkes, S. L. Cooper, J. Biomed. Mater. Res. 1994, 28, 329

[20] E. S. Place, N. D. Evans, M. M. Stevens, Nat. Mater. 2009, 8, 457

[21] C. Hepburn, Polyurethane Elastomers, Springer Science \& Business Media, Dordrecht 2012.

[22] M. Modesti, A. Lorenzetti, Eur. Polym. J. 2001, 37, 949.
[23] L. Aubert, M. Dubus, H. Rammal, C. Bour, C. Mongaret, C. Boulagnon-Rombi, R. Garnotel, C. Schneider, R. Rahouadj, C. Laurent, S. C. Gangloff, F Velard, C Mauprivez, H. Kerdjoudj, Int. J. Mol. Sci. 2017, 18, 2210.

[24] M. F. Butler, A. M. Donald, W. Bras, G. R. Mant, G. E. Derbyshire, A. J. Ryan, Macromolecules 1995, 28, 6383.

[25] P. Lindner, T. Zemb, Neutron, X-Ray and Light Scattering: Introduction to an Investigative Tool for Colloidal and Polymeric Systems, North-Holland, 1991, ISBN: 0444889469.

[26] D. W. Van Krevelen, K. Te Nijenhuis, Properties of Polymers: Their Correlation with Chemical Structure; Their Numerical Estimation and Prediction from Additive Group Contributions, Elsevier, Amsterdam 2009.

[27] R. J. Zdrahala, R. M. Gerkin, S. L. Hager, F. E. Critchfield, J. Appl. Polym. Sci. 1979, 24, 2041.

[28] D. E. Discher, P. Janmey, Y. Wang, Science 2005, 310, 1139

[29] I. R. Clemitson, Castable Polyurethane Elastomers, CRC Press, Boca Raton 2015.

[30] M. M. Bernal, M. A. Lopez-Manchado, R. Verdejo, Macromol. Chem. Phys. 2011, 212, 971.

[31] H. Okuto, Die Makromolekulare Chemie 1966, 98, 148.

[32] S. C. Yoon, B. D. Ratner, Macromolecules 1988, 21, 2392.

[33] H.-B. Lin, C. Garcia-Echeverria, S. Asakura, W. Sun, D. F. Mosher, S. L. Cooper, Biomaterials 1992, 13, 905.

[34] Y. Deslandes, G. Pleizier, D. Alexander, P. Santerre, Polymer 1998, 39, 2361

[35] B. S. Kim, H. Y. Jeong, B. K. Kim, Colloids Surf. A 2005, 268, 60.

[36] K. Nakamae, T. Nishino, S. Asaoka, Sudaryanto, Int. J. Adhes. Adhes. 1996, 16, 233.

[37] D. K. Chattopadhyay, B. Sreedhar, K. V. S. N. Raju, J. Polym. Sci., Part B: Polym. Phys. 2006, 44, 102.

[38] L. Ning, W. De-Ning, Y. Sheng-Kang, Polymer. 1996, 37, 3577.

[39] A. J. Ryan, W. R. Willkomm, T. B. Bergstrom, C. W. Macosko, J. T. Koberstein, C. C. Yu, T. P. Russell, Macromolecules 1991, 24, 2883.

[40] S. Velankar, S. L. Cooper, Macromolecules 1998, 31, 9181.

[41] J. T. Koberstein, R. S. Stein, J. Polym. Sci.: Polym. Phys. Ed. 1983, 21, 1439 .

[42] L. J. Buckley, P. T. Hammond, M. F. Rubner, Macromolecules 1993, 26, 2380.

[43] J. T. Garrett, J. S. Lin, J. Runt, Macromolecules 2002, 35, 161.

[44] J. T. Garrett, J. Runt, J. S. Lin, Macromolecules 2000, 33, 6353.

[45] C. H. Kim, M. S. Khil, H. Y. Kim, H. U. Lee, K. Y. Jahng, J. Biomed. Mater. Res. Part B Appl. Biomater 2006, 78B, 283.

[46] M. R. Alexander, P. Williams, Biointerphases 2017, 12, 02 C201.

[47] M. J. Hearn, B. D. Ratner, D. Briggs, Macromolecules 1988, 21, 2950.

[48] S. Hsu, Y.-C. Kao, Macromol. Biosci. 2004, 4, 891.

[49] L.-C. Xu, J. Runt, C. A. Siedlecki, Acta Biomater.. 2010, 6, 1938.

[50] J. G. Archambault, J. L. Brash, Colloids Surf., B 2004, 33, 111.

[51] T. K. Kwei, J. Appl. Polym. Sci. 1982, 27, 2891.

[52] T.-L. Wang, T.-H. Hsieh, Polym. Degrad. Stab. 1997, 55, 95.

[53] K. Gisselfält, B. Helgee, Macromol. Mater. Eng. 2003, 288, 265.

[54] J. W. C. Van Bogart, P. E. Gibson, S. L. Cooper, J. Polym. Sci.: Polym. Phys. Ed. 1983, 21, 65.

[55] A. Saiani, C. Rochas, G. Eeckhaut, W. A. Daunch, J.-W. Leenslag, J. S. Higgins, Macromolecules 2004, 37, 1411.

[56] M. J. Dalby, M. O. Riehle, H. J. H. Johnstone, S. Affrossman, A. S. G. Curtis, Tissue Eng. 2002, 8, 1099.

[57] M. J. Dalby, N. Gadegaard, R. Tare, A. Andar, M. O. Riehle, P. Herzyk, C. D. W. Wilkinson, R. O. C. Oreffo, Nat. Mater. 2007, 6, 997.

[58] R. Tzoneva, M. Heuchel, T. Groth, G. Altankov, W. Albrecht, D. Paul, J. Biomater. Sci., Polym. Ed. 2002, 13, 1033.

[59] T. H. Groth, K. Klosz, E. J. Campbell, R. R. C. New, B. Hall, H. Goering, J. Biomater. Sci., Polym. Ed. 1995, 6, 497. 